\title{
Sphingolipids in the Heart: From Cradle to Grave
}

\author{
Anna Kovilakath ${ }^{1 \dagger}$, Maryam Jamil ${ }^{1 \dagger}$ and Lauren Ashley Cowart ${ }^{2,3 *}$ \\ ${ }^{1}$ Department of Human and Molecular Genetics, Virginia Commonwealth University, Richmond, VA, United States, \\ ${ }^{2}$ Department of Biochemistry and Molecular Biology and the Massey Cancer Center, Virginia Commonwealth University, \\ Richmond, VA, United States, ${ }^{3}$ Hunter Holmes McGuire Veteran's Affairs Medical Center, Richmond, VA, United States
}

Cardiovascular diseases are the leading cause of mortality worldwide and this has largely been driven by the increase in metabolic disease in recent decades. Metabolic disease alters metabolism, distribution, and profiles of sphingolipids in multiple organs and tissues; as such, sphingolipid metabolism and signaling have been vigorously studied as contributors to metabolic pathophysiology in various pathological outcomes of obesity, including cardiovascular disease. Much experimental evidence suggests that targeting sphingolipid metabolism may be advantageous in the context of cardiometabolic disease. The heart, however, is a structurally and functionally complex organ where bioactive sphingolipids have been shown not only to mediate pathological processes, but also to contribute to essential functions in cardiogenesis and cardiac function. Additionally, some sphingolipids are protective in the context of ischemia/reperfusion injury. In addition to mechanistic contributions, untargeted lipidomics approaches used in recent years have identified some specific circulating sphingolipids as novel biomarkers in the context of cardiovascular disease. In this review, we summarize recent literature on both deleterious and beneficial contributions of sphingolipids to cardiogenesis and myocardial function as well as recent identification of novel sphingolipid biomarkers for cardiovascular disease risk prediction and diagnosis.

Keywords: sphingolipids, ceramide, sphingosine-1-phosphate, heart development, cardiovascular disease

\section{INTRODUCTION}

Sphingolipids, which constitute a large and diverse lipid class, were originally recognized over a century ago as structural components of cell membranes. More recently they are recognized as crucial bioactive lipids that regulate many cell processes (1). Sphingolipid biosynthesis commences with condensation of an amino acid with acyl-CoA to yield an amino alcohol, or sphingoid base, which is the defining structural component of the sphingolipid class. The sphingoid base can subsequently be modified by acylation, phosphorylation, glycosylation, and/or addition of multiple headgroups or other functional groups $(2,3)$. These structural modifications generate hundreds of sphingolipid subspecies involved in most if not all major aspects of cell regulation including cell division and senescence, migration, differentiation, apoptosis, autophagy, nutrient uptake, metabolism, and protein synthesis (1). Commensurate with their multiple regulatory roles, disruption of sphingolipid metabolism has emerged as a component of many diseases including cardiometabolic disease. As such, sphingolipid metabolism may be a suitable therapeutic target in the context of cardiovascular disease (CVD). However, perhaps less appreciated are the constitutive and protective roles of sphingolipids in some contexts including heart development 
and ischemic injury, and these desirable and homeostatic roles should be considered for both in vivo experimental design and, more importantly, developing pharmacologic strategies for clinical use. A comprehensive awareness of both deleterious and beneficial roles of sphingolipids will inform successful therapeutic approaches based on targeting sphingolipid metabolism.

\section{SPHINGOLIPID BIOSYNTHESIS: A BRIEF OVERVIEW}

De novo synthesis of sphingolipids starts in the endoplasmic reticulum (ER) where the enzyme serine palmitoyltransferase (SPT) catalyzes the condensation of an amino acid with acylCoA into 3-ketodihydrophingosine (KDHSph). The second step occurs through 3-Ketodihydrosphingosine reductase, which rapidly converts KDHSph to dihydrosphingosine (DHS). DHS is the first easily detected sphingolipid metabolite and serves as the sphingoid base for synthesis of ceramides and downstream complex sphingolipids. DHS can be phosphorylated (forming DHS-1-phosphate) but more often undergoes $\mathrm{N}$-acylation. This is accomplished by a family of (dihydro)ceramide synthase enzymes (CerS) consisting of 6 isoforms with various enzymological distinctions including partially distinct substrate preferences for the incorporation of fatty acids with different chain lengths (4-6). In mammals the length of the ceramide acyl chain length ranges from medium (12-14C), long (16-20C), very long (22-26C), and ultra-long chain fatty acids (>26C). Dihydroceramide (DHC) is converted into ceramide by $\mathrm{DHC}$ desaturase (DES), which introduces a double bond into the sphingoid base. Once formed, ceramide can be hydrolyzed by ceramidase enzymes, yielding sphingosine, which can be reincorporated into ceramides by CerS or phosphorylated by sphingosine kinases (SphK1 and SphK2) to produce sphingosine1-phosphate. Ceramide can also undergo phosphorylation, yielding ceramide-1-phosphate, or O-acylation, yielding a structure similar to a triacylglycerol (TAG), and similarly, is stored in lipid droplets (7). Most ceramide, however, is shuttled to the Golgi apparatus via vesicular transport or ceramide transport protein (CERT) for further metabolism to complex sphingolipids including glycosphingolipids (GSLs) and sphingomyelins (SM) through the addition of sugars or phosphocholine, respectively. These complex sphingolipids can be catabolized to yield ceramide, which plays an essential role in regulating cell ceramide profiles. A less well-studied pathway of sphingomyelin catabolism generates sphingosylphosphorylcholine (SPC). SPC is composed of a long-chain sphingosine and phosphorylcholine and is essentially lyso-sphingomyelin, thus sharing similar structure with S1P and other lysophospholipids. Phosphorylated sphingoid bases are the only known sphingolipids that can exit the cell sphingolipid pool. This occurs via S1P lyase (SPL) which catabolizes S1P into non-sphingolipid components; fatty aldehyde and ethanolamine phosphate. Because SPL is the only exit from the sphingolipid metabolic pathway, it has been proposed as a major regulator of total cell sphingolipid levels (8).
The diversity of sphingolipid species arises not only from the length of the $\mathrm{N}$-acyl chain of ceramide and its derivatives or the functional groups added to the sphingoid base, but also from the length of the sphingoid base. Synthesis of the sphingoid base occurs through SPT, a multimeric enzyme comprised of catalytic subunits and various regulatory proteins. SPTLC1 and SPTLC2 form the canonical catalytic complex, but SPTLC3 can also be included and/or substitute for SPTLC2. The composition of the SPT complex determines substrate and product specificity. The SPTLC1/SPTLC2 complex condenses serine with palmitoyl-CoA giving rise to canonical sphingolipids with an 18-carbon sphingoid backbone (d18:0 DHS) (9). In contrast, inclusion of SPTLC3 in the SPT complex renders a more promiscuous enzyme, using 14-carbon myristoyl-CoA, 18-carbon stearoyl-CoA, and potentially others. This seems to be regulated at least in part by inclusion of small SPT subunits (ssSPTa and b) in the SPT complex (10). These bases are also incorporated into downstream sphingolipids, though not evenly across all sphingolipid species (11). Importantly, variations in both sphingoid base and $\mathrm{N}$-acyl chain determine biological functions $(3,12)$. Several proteins, namely, neurite outgrowth inhibitor (Nogo-A/B) and orosomucoid-like proteins (ORMDL) negatively regulate SPT. Upon their respective ablation or inhibition, the resulting heart phenotype drastically varies, suggesting sphingolipid levels from de novo synthesis must be within a narrow range to maintain normal heart homeostasis (13-15). In the cardiovascular system, many sphingolipid subclasses and even specific molecules have distinct functions, some of which are desirable and others deleterious; for example, increased ceramide and SM oftentimes with concomitant decrease of S1P have been implicated in dilated cardiomyopathy, diabetic cardiomyopathy (DbCM), ischemic heart disease (IHD), and myocarditis (16-20). Therefore, the alterations that occur in sphingolipid content and profiles in disease contexts have emerged as a central focus in cardiovascular biology.

\section{SPHINGOLIPIDS IN HEART DEVELOPMENT AND THE CARDIAC CONDUCTION SYSTEM}

Multiple processes are involved in forming the heart, which is the first functional organ in vertebrate embryos. Cardiogenesis begins with formation and positioning of the primitive heart tube followed by heart looping, and finally chamber and septal formation (Summarized in Figure 1). In the context of cardiovascular biology, sphingolipids, especially ceramides, are most often considered deleterious; however, data show that the sphingosine kinase/sphingosine-1-phosphate signaling pathway is essential for heart development.

Studies in both zebrafish and mice support a regulatory function for sphingosine-1-phosphate (S1P) in formation and positioning of the primitive heart tube. Sphingosine produced by hydrolytic de-acylation of ceramides can be phosphorylated by sphingosine kinases (SphKs) to produce S1P, which signals 


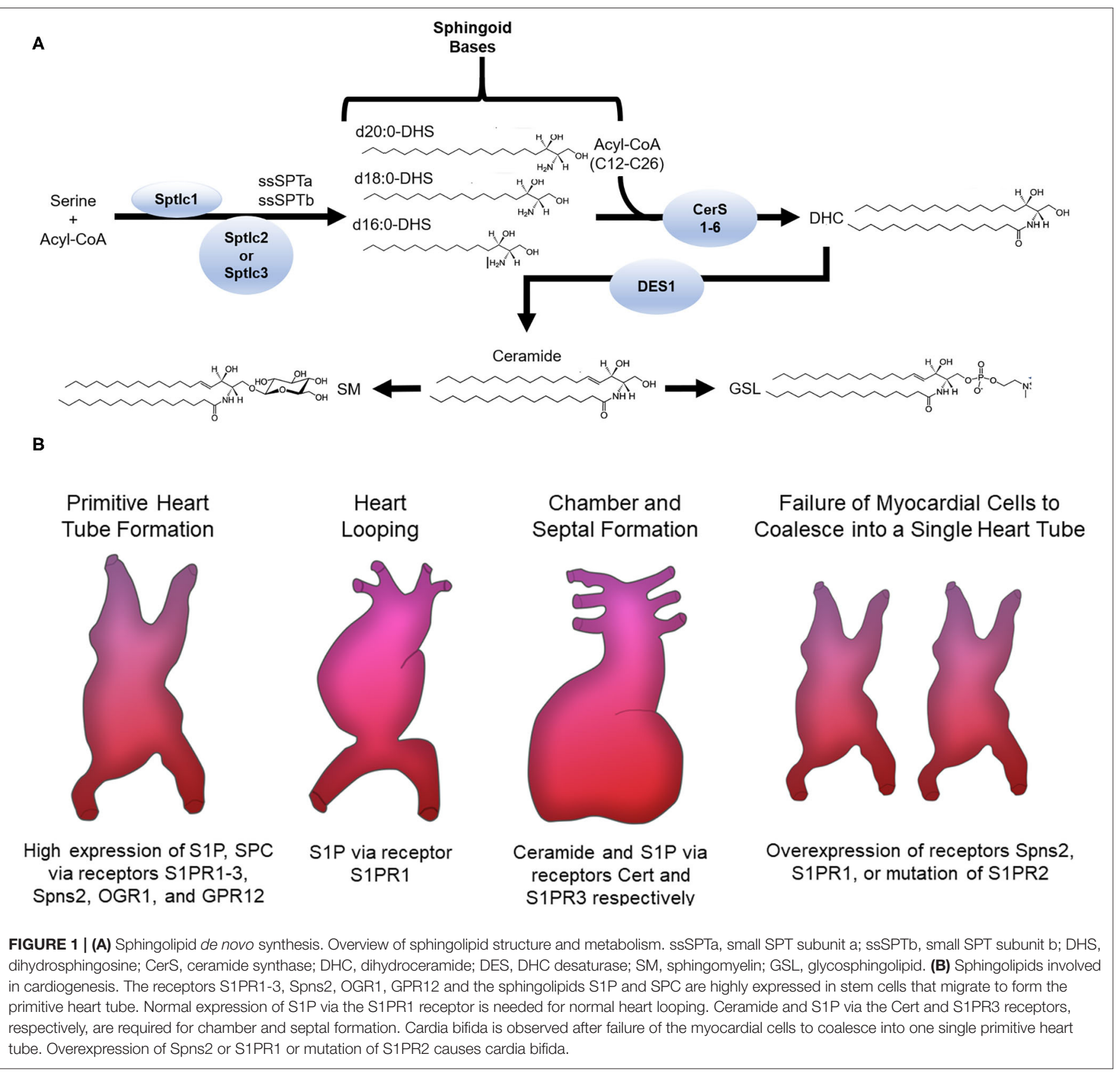

through endocrine, paracrine, and autocrine mechanisms depending on context (21). For endocrine and paracrine functions S1P is transported into the extracellular milieu through plasma membrane ATP binding cassette family members (ABC) or spinster two (Spns2) transporters where it then signals through one of five different $G$ protein-coupled receptors (S1PR1-5) (21). In Zebrafish, mutations in s1pr2, but not any of the other S1P receptors, led to cardia bifida or formation of two laterally positioned hearts (22) (Summarized in Figure 1). This phenotype was also observed in multiple studies with a spns2 mutant or overexpression of slprl (22-29). In mice, conditional knockout (KO) of S1PR1 caused embryonic lethality due to ventricular non-compaction, ventricular septal defects, absence of normal increase in the number of cardiomyocytes and decreased myofibril organization (28). These studies suggest S1P signaling components S1PR1, S1PR2, and Spns2 are necessary for cardiomyocyte expansion and myocardial precursor migration to the ventral midline of the embryo where they develop into the primitive heart tube. At later developmental stages, knockdown of the zebrafish gene homolog to s1prl caused an improperly looped heart $(30,31)$. Another study showed that an s1pr1 morpholino in zebrafish affected heart valve orientation, an indicator of incorrect looping (28). During the looping process, precursors of cardiac valves-endocardial 
cushioning (EC) and atrioventricular canal (AV)-are also formed. In mice, S1PR1-/-, but not S1PR2 or S1PR3 KO, resulted in embryonic lethality due to severe heart hemorrhaging $(32,33)$. This may arise from the well-known role of this receptor in maintaining cell-cell contacts in the vascular endothelium (34). In mouse whole embryo cultures, inhibition of sphingosine kinase led to cell death, but elevating S1P levels prevented differentiation of cells into distinct cardiac cell types (35). These studies show that appropriate concentrations of S1P must be maintained for normal development of cardiac valve precursors. It should be noted, however, that affinities of $\mathrm{S} 1 \mathrm{P}$ receptors for $\mathrm{S} 1 \mathrm{P}$ are in the nanomolar range (e.g., 50-250 nM) and therefore, effects observed with higher concentrations in vitro may arise from non-specific activity, for example cross-reactivity with other lysophospholipid receptors, or even gross membrane perturbations due to the detergent properties of S1P. Therefore, care must be taken in interpreting data from experiments using supraphysiological S1P concentrations.

In addition to development, cardiac function also suffers from perturbed sphingolipid synthesis. For example, mouse embryos treated with exogenous $\mathrm{S} 1 \mathrm{P}$ exhibited sinus bradycardia (decreased heart rate) $(35,36)$. In addition, S1PR3 KO mice treated with FTY720, an S1P receptor agonist known to cause sinus bradycardia in humans, did not show altered heart rates, whereas arrhythmias were observed in S1PR3 knockin (KI) mice (36). S1PR3 is expressed on neural crest-derived atrioventricular nodes (AVN), His bundles, cardiac Purkinje fibers and vascular smooth muscles of the coronary arteries in mice. Extensive studies have suggested S1P plays a multifaceted role as a primary and secondary messenger in regulating both calcium and potassium ion channels $(37,38)$. This suggests S1P binds its receptor, S1PR3 within the AVN conduction block to regulate intracellular calcium and potassium levels which in turn alter the heart rate (39-41). Taken together these studies show broad roles for S1P receptors in the cardiac conduction system.

SPC displays cross-reactivity to S1P receptors due to its structural similarity to $\mathrm{S} 1 \mathrm{P}$. In addition, SPC also signals via OGR1 and GPR12 receptors (42). SPC, like S1P, is important for heart development, playing a pivotal role for end stage differentiation of committed multipotent cardiovascular progenitors to cardiomyocytes, vascular smooth muscle and endothelial cells (43). Importantly, SPC also induced differentiation of resident cardiac stem cells to cardiomyocytes, a finding which may hold tremendous therapeutic potential (44), as there is currently great interest in therapeutic strategies that leverage the potential for stem cell differentiation to cardiomyocytes in treating cardiac injury. In sum, several lines of evidence point to essential functions of S1P, SPC and their respective receptors in normal heart development and function (summarized in Table 1). Therefore, while sphingolipids have largely been implicated in cardiac pathology, they make essential contributions to cardiogenesis and therefore a broader cognizance of sphingolipids in the heart may benefit efforts to develop sphingolipid-based therapeutic approaches.

\section{SPHINGOLIPIDS IN CARDIOVASCULAR DISEASE}

Cardiovascular diseases (CVDs) are the leading cause of death in USA and worldwide, and it is estimated that by 2030 upward of $40 \%$ of the American population will be afflicted with some form of CVD (64). CVD occurs largely in the context of metabolic disease, such as diabetes, and obesity which are known to reconfigure sphingolipid profiles in multiple organs and tissues. It is unsurprising, then that a wide spectrum of sphingolipid species have been implicated in the pathophysiology of numerous CVDs $(65,66)$.

\section{Myocardial Lipotoxicity}

It is now well-established that ceramide metabolism is altered in the context of type 2 diabetes mellitus (T2DM) and obesity which are both linked to CVD (67-69). In fact, higher plasma ceramide levels have been associated with visceral obesity, non-alcoholic fatty liver disease, and T2DM, which are also predictors of CVDs (70-76). Genetically modified mouse models of lipotoxicity have greatly facilitated understanding of sphingolipid contributions to lipotoxic cardiomyopathy (The outcomes of many of these lipotoxic animal models are summarized in Table 1). In fact, the first recognition of a potential link between sphingolipids and cardiac lipotoxicity arose from mice with cardiomyocytespecific overexpression of long-chain acyl-CoA synthetase (77). This increased lipid uptake generated a lipotoxic cardiomyopathy phenotype. Hearts from these mice showed increased TAG concomitant with increased lipid droplets $(77,78)$. Because increased cell death was observed in these mice the investigators measured total ceramide, a known apoptotic mediator, and found a $50 \%$ increase in total ventricular ceramide content. Metabolic disease increases uptake, utilization, and storage of fatty acids in lipid droplets, but the potential toxicity of lipid droplets/TAG, or other lipids remained in question. To address this, a followup study crossed these transgenic mice with another strain overexpressing diacylglycerol acyltransferase 1 (DGAT1), which increased intracellular TAG and reduced ceramide (79). Because DGAT1 catalyzes the final step in TAG synthesis, it diverts Acyl-CoA into neutral sphingolipid pools, thereby reducing toxic lipids in myocardial lipotoxicity such as ceramides (80, 81). Long-chain acyl-CoA synthetase 1 (ACSL1) catalyzes the conversion of long-chain fatty acids to fatty acyl-CoAs, which are then used as substrates by SPT in de novo sphingolipid biosynthesis (82). Thus, crossing the DGAT1 mice with the acyl coenzyme A synthetase-1 (ACSL1) transgenic mice increased TAG and lipid droplets, but lowered ceramides and improved the cardiac phenotype of ACSL1 mice, indicating that triacylglycerols (TAGs) are not lipotoxic per se but serve as an indicator of lipid oversupply (83). These studies and others gave rise to the concept that routing of lipids into TAGs could decrease their incorporation into bioactive lipids and therefore improve cardiac outcomes of lipotoxicity; however, whether sphingolipids per se were the underlying toxic lipid species remained to be addressed.

The first studies to effectively identify a mechanistic link between ceramide and lipotoxic cardiomyopathy employed mice with transgenic overexpression of a GPI-anchored lipoprotein 
TABLE 1 | Sphingolipid knockout models and their cardiac tissue phenotypes.

\begin{tabular}{|c|c|c|}
\hline Animal model & Cardiac tissue phenotype & References \\
\hline $\begin{array}{l}\text { Constitutive heterozygous Spt/c1 knockout \& } \\
\text { glycosylphosphatidylinositol (GPI)-anchored human lipoprotein } \\
\text { lipase transgenic }\end{array}$ & $\begin{array}{l}\text { - Decreased cardiac ceramides comparable to WT mice } \\
\text { - Prevention of lipotoxic cardiomyopathy induced by } \\
\text { glycosylphosphatidylinositol (GPI)-anchored human lipoprotein } \\
\text { lipase knockout }\end{array}$ & (16) \\
\hline Cardiomyocyte-specific Sptlc2 knockout & $\begin{array}{l}\text { - Decreased C18:0 and very long chain ceramides } \\
\text { - Increased ER stress markers } \\
\text { - Increased apoptosis } \\
\text { - Upregulation of heart failure markers } \\
\text { - Decreased fractional shortening } \\
\text { - Thinner cardiac walls }\end{array}$ & $(45,46)$ \\
\hline Constitutive $\alpha$-galactosidase A knockout (Fabry disease) & $\begin{array}{l}\text { - Progressive accumulation of globotrioasylceramide in aged mice } \\
\text { - Decreased glucosylceramides } \\
\text { - No alteration in total ceramide }\end{array}$ & $(47,48)$ \\
\hline Constitutive Smpd1 knockout & - Accumulation of aSMase in aged mice & (49) \\
\hline Constitutive mutant Spns2 allele (zebrafish) & $\begin{array}{l}\text { - Cardia bifida } \\
\text { - Shortened anterior-posterior distance in the ventral pharyngeal arch } \\
\text { - Embryonic lethality }\end{array}$ & (30) \\
\hline Constitutive SphK1 knockout & $\begin{array}{l}\text { - Decreased S1P levels } \\
\text { - Poor animal resuscitation after cardiac arrest } \\
\text { - Impaired survival post-resuscitation after cardiac arrest } \\
\text { - Increased infarct sizes after l/R }\end{array}$ & $(52,53)$ \\
\hline Constitutive maternal and zygotic SphK2 knockout (zebrafish) & $\begin{array}{l}\text { - Cardia bifida } \\
\text { - Failure of cardiac progenitor migration to form primitive heart tube } \\
\text { - Decreased S1P levels }\end{array}$ & (54) \\
\hline Cardiomyocyte-specific S1pr1 knockout & $\begin{array}{l}\text { - Ventricular non-compaction } \\
\text { - Ventricular septal defects } \\
\text { - Perinatal lethality } \\
\text { - Decreased cardiomyocyte proliferation } \\
\text { - Decreased myofibril organization } \\
\text { - No alteration in coronary I/R injury }\end{array}$ & (55) \\
\hline Constitutive mutant s1pr2 allele (zebrafish, mil) & $\begin{array}{l}\text { - Cardia bifida } \\
\text { - Failure of cardiac progenitor migration to form primitive heart tube } \\
\text { - Embryonic lethality }\end{array}$ & (22) \\
\hline Cardiomyocyte-specific S1pr3 knockout & - No alteration in coronary I/R injury & (57) \\
\hline Constitutive S1pr2 \& S1pr3 double knockout & $\begin{array}{l}\text { - Increased infarct size after I/R injury } \\
\text { - Perinatal lethality }\end{array}$ & $(58,59)$ \\
\hline Constitutive S1pr2 \& ApoE double knockout & $\begin{array}{l}\text { - Decreased atherosclerotic lesions } \\
\text { - Decreased number of macrophages in lesions }\end{array}$ & (60) \\
\hline Constitutive S1pr3 \& ApoE double knockout & $\begin{array}{l}\text { - No change in atherosclerotic lesions } \\
\text { - Decreased number of macrophages in lesions }\end{array}$ & $(61,62)$ \\
\hline Constitutive Cert knockout & $\begin{array}{l}\text { - Severely compromised cardiac function } \\
\text { - Accumulation of ceramide } \\
\text { - Embryonic lethality }\end{array}$ & (63) \\
\hline
\end{tabular}

lipase on the cardiomyocyte surface ( $\mathrm{LpL}^{\mathrm{GPI}}$ ) (78). Lipoprotein lipase $(\mathrm{LpL})$ degrades circulating TAGs into free fatty acids, thus increasing fatty acids to cardiomyocytes. Similar to the ACSL1 mice, these mice showed a robust lipotoxic cardiomyopathy phenotype. These mice were treated with an inhibitor of de novo sphingolipid biosynthesis, myriocin, which lowered ceramide and ameliorated the phenotype. Additionally, crossing the $\mathrm{LpL}^{\mathrm{GPI}}$ mice to mice haploinsufficient in SPTLC1, which mediates de novo sphingolipid synthesis, showed a similar effect (16). These studies suggest that in the lipotoxic context, 
sphingolipid synthesis is deleterious, and increased incorporation of fatty acids into TAG is cardioprotective. This would imply that myocardial TAG levels are not indicative of cardiac dysfunction but rather reflect lipid metabolic dysfunction within the heart.

These studies were highly informative and led our lab to investigate specific sphingolipid species that may play roles in lipotoxic cardiomyopathy and the mechanism(s) by which they contributed. Based on our previous studies on the effects of saturated vs. unsaturated fatty acids on sphingolipid metabolism, we developed a high saturated fat diet (8486). Mice on this high fat diet exhibited elevations in total myocardial ceramides and also DbCM-like cardiac hypertrophy and dysfunction (87). Further examination of specific ceramide chain lengths revealed that $\mathrm{C} 14: 0$ ceramide as well as very long-chain (VLC) ceramides increased specifically in the high saturated fat-fed mice compared to mice on control and lard diets. Reducing sphingolipid synthesis by inhibition of SPT with Myriocin treatment inhibited sphingolipid synthesis including C14:0 ceramide production and also restored cardiac function. These animals also showed increased autophagosomes in cardiomyocytes; indeed, treatment of cultured primary cardiomyocytes with myristate (C14:0) increased autophagy. As noted above, ceramide synthase enzymes have partially distinct substrate preferences, and C14:0 ceramide is a product of CerS5, while VLC ceramides are products of CerS2. Indeed, overexpression of CerS5 in cardiomyocytes increased autophagic flux, and treating cardiomyocytes lacking CerS5 with myristate did not increase autophagy. These studies were the first to identify a specific ceramide species and ceramide synthase isoform in cardiac lipotoxicity. Upon overexpression of CerS2, VLC ceramides were elevated inducing insulin resistance, oxidative stress, mitochondrial dysfunction and mitophagy. As gain and loss-of function studies targeting CerS5 had no effect on these same functions, a distinct role was established for CerS2 $(87,88)$. These studies established specific roles for subsets of ceramide species and/or CerS enzymes in lipotoxic outcomes in the context of high fat feeding and subsequent diabetes (87, 88). Though these studies were conducted in mice and various primary and cultured cardiomyocyte models, the findings may nonetheless bear some relevance to humans (45). Importantly, many of these studies addressed lipotoxicity in the context of metabolic disease; however, other cardiac insults also cause lipotoxicity, and this may proceed by alternative mechanisms (69-76, 89). For example, metabolic tracing studies in mice subjected to pressure overload via transverse aortic constriction (TAC) showed that transgenic overexpression of acyl coenzyme A synthetase-1 (ACSL1) mitigated heart dysfunction relative to WT mice (83). In this context, ACSL1 overexpression prevented de novo synthesis of C16-, C24-, and C24:1-ceramides, which are synthesized by CerS5 and CerS2, respectively, but increased C20- and C22-ceramides. These subspecies can be generated by CerS4 and therefore, CerS4-derived ceramides may have a distinct, protective function in the context of $\mathrm{HF}$, though this remains to be tested.

In addition to the n-acyl chain length, dictated by CerS, we showed that the sphingoid base chain length also distinguishes activities of sphingolipids. While the canonical SPT complex includes SPTLC1 and 2, SPTLC3 is an alternate subunit that can substitute for SPTLC2 and alter sphingoid base chain length. Therefore, the SPTLC1/2 complex generates an 18carbon sphingoid base, but inclusion of SPTLC3 alters substrate preference to generate sphingoid bases of alternate chain lengths. We showed that high saturated fat feeding in mice induced SPTLC3 and altered cell sphingolipid profiles to include a high proportion of sphingolipids containing a 16-carbon sphingoid base within the myocardium (11). This shortened base did not cause autophagy but rather led to apoptotic cell death in cardiomyocytes, further exemplifying how distinct sphingolipid molecules can have divergent effects. Emerging literature continues to build a case for a role for SPTLC3 in human CVDs. Interestingly, a study of three German populations linked single nucleotide polymorphisms (SNPs) in the SPTLC3 locus to MI (90). Another study identified 28 SNPs close to the SPTLC3 locus which were significantly associated with reduced C22:0 and C24:0 ceramide concentrations, which are thought to correlate with disease risk (91).

Initial studies including our own showed that inhibition of overall sphingolipid biosynthesis prevented cardiac lipotoxicity, suggesting that merely reducing ceramide in the lipotoxic heart may be a "magic bullet." However, rather than improving cardiac function, a cardiomyocyte-specific SPTLC2 null mouse showed an exacerbated cardiac phenotype (46). While the mechanism for this was not revealed in that study, a speculative hypothesis is that SPTLC3 may show compensatory upregulation in the context of SPTLC2 depletion. If so, this could explain the phenotype observed in the SPTLC2 depletion mouse model. These studies coupled with observations of cardioprotection in TAC correlating to increased C20:0 and C22:0 ceramides clearly demonstrate that roles of ceramides in cardiac pathology are complex. In addition to ceramides, however, alterations in dihydroceramides, ceramide-1-phopshates, sphingomyelins, and glycosphingolipids likely play disparate roles in cardiac pathology, and genetic manipulations or use of myriocin in vivo does not necessarily enable identification of specific lipid classes involved in pathological processes. Further research is required to fully understand the links between specific sphingolipid pools and molecular structures and deleterious outcomes through modulation of cell signaling.

\section{Coronary Artery Disease}

Coronary Artery Disease (CAD) or IHD is the most common type of CVD worldwide and has been the leading cause of death for the past 16 years. CAD is caused by narrowing of arteries and subsequent reduction of blood flow to the heart due to build-up of plaque (atherosclerosis) within the arteries of the heart, ultimately leading to heart failure (HF). More often than not, coronary atherosclerosis observed in CAD occurs in the context of metabolic disease. As a result of chronic CAD, myocardial infarction (MI) and HF often occur. In contrast to much literature implicating ceramides as inducers of CVDs, pronounced cardiogenic and cardioprotective properties have been attributed to S1P (92-101).

Current therapeutics already undergoing clinical trials for $\mathrm{CAD}$, ischemia/reperfusion injury, $\mathrm{MI}$ and $\mathrm{HF}$ target the 
S1P/SphK axis, specifically drugs targeting S1P receptors (102104). Mice with combined deletion of S1PR2 and S1PR3 subject to ischemia/reperfusion injury showed increased infarct size, however, infarct size was not altered when either S1PR2 or S1PR3 was deleted $(58,105)$. However, another study showed that intravenous SPC treatment of S1PR3 null mice subject to IR injury reduced infarct size (106). Agonists specific to S1PR1 protected mouse cardiomyocytes from hypoxia, while the opposite effect was observed with S1PR1 antagonists (107-111). Another study showed that S1PR1 attenuated cardiac fibrosis and hypertrophy in mice with HF induced by TAC (112). Nogo-A/B deficient mice were protected from HF for up to 3 months after TAC, while also seeing a significant induction of S1P (14).

In mouse, rabbit and rat models of ischemia/reperfusion injury (IRI) it was noted that ceramide, membrane neutral sphingomyelinase (nSMase) and acidic sphingomyelinase (aSMase) increased in the infarct site and blood with concomitant decrease of S1P (113-120). Ischemic preconditioning with S1P is a tried and proven method to induce significant recovery of cardiac function and infarct reduction in IRI (57, 121-123). The absence of improved cardiac function in SphK1 and SphK2 ablated mice subject to IR levels suggest the significance of S1P in ischemic conditioning $(121,124)$. These studies suggest targeting the S1P-SphK axis satisfies the criterion as an effective therapeutic agent to overcome the damages elicited by IRI. Though further investigation into the crosstalk between S1P receptors and analogs signaling behavior in comorbidities would better optimize the therapeutic potential of S1P in IRI.

Multiple in vitro studies observed upregulation of aSMase and nSMase along with increased SM in animal models of HF $(125,126)$. The nSMase and aSMase hydrolyze sphingomyelin to release ceramide, and thus the accumulation of ceramide in post-ischemic heart may arise from SM catabolism and not de novo sphingolipid biosynthesis $(127,128)$. Another study in both mice and humans with HF noted increased levels of SPTLC2, which participates in de novo sphingolipid synthesis and likely contributes to the significant increase of total ceramides in the aforementioned studies (45). However, this same study did not note any changes in aSMase or nSMase in HF, the primary catabolic enzymes for ceramide production (45). Therefore, it may be that chronic conditions leading to HF increase de novo synthesis, while acute insults such as MI activate sphingolipid catabolism, though there are clear exceptions to this concept, including nSMase activity was increased $2-3$ months post-MI and SPTLC2 was observed to increase 2 weeks post-MI $(45,127)$.

While the roles of ceramides and S1P are well-established and antagonistic in CVDs, some literature suggests sphingosine plays a dichotomous role as a cardio protectant and CVD inducer. Induction of sphingosine in patients with and animal models of IRI points toward the maladaptive role of sphingosine in CVDs $(129,130)$. However, the same group preconditioned animals with sphingosine prior to ischemia or perfusion resulting in massive reduction of infarct size. This contradictory evidence points toward sphingosine as a cardio protectant in CVDs (131). Importantly, sphingosine can be used as a substrate for generation of either ceramides or S1P; therefore, whether it is protective or deleterious may arise from its metabolic fate.
However, sphingosine does have its own signaling functions and thus may make these contributions directly and without further metabolism (132-134).

\section{SPHINGOLIPIDS AS EMERGING BIOMARKERS IN ASSESSING CARDIOVASCULAR DISEASE}

Over the past several decades various heart studies including the Framingham Heart Study, Busselton Family Heart Study, Strong Heart Family Study, Utah CAD and others have sought to determine CVD development, risks and therapeutics all aimed at combating CVD. As a result, conventional risk factors such as age, sex, ethnicity, blood pressure, total triglyceride levels and total cholesterol levels emerged as biomarkers for risk of major adverse cardiac events. However, given the substantial and rising burden of CVDs, ongoing efforts to shed light on novel, more specific biomarkers for CVD are needed. In response to this need, more sensitive lipidomics analysis have been developed focusing on sphingoid base and acyl chain length composition of total sphingolipids. Using these advanced techniques, risk assessment scores utilizing sphingolipid species levels have been recently developed in detecting CVDs and they continuously outperform conventional cardiovascular risk markers (135). For example, A Busselton Family Heart Study identified many classes of the sphingolipid species ceramides, DHC, mono-, di- and trihexosylceramides, SM, GM1, GM3 and sulfatides associated with heritable cardiac events, most of which were positively genetically correlated with LDL, HDL, total cholesterol and negatively correlated with triglyceride levels. In another study, the serum of patients with a clinical diagnosis of $\mathrm{HF}$ with preserved ejection fraction (HFpEF), the most common form of $\mathrm{HF}$ and also strongly associated with diabetes, in The Alberta Heart Failure Etiology and Analysis Research Team (HEART) project showed reduced SM compared to non-HF controls (136). These sphingolipids seemed to have no relationship to conventional risk factors such as diastolic blood pressure, systolic blood pressure, BMI and waist-hip ratio, suggesting they may be used as more specific markers to identify high-risk patients especially likely to have CVD (137-140).

A growing body of literature suggests long-chain ceramides and very long-chain ceramides and SM are associated with adverse cardiac outcomes. Ceramide analysis on an aggregate of 29,818 individuals from 7 cohort studies and determined plasma Ceramide (d18:1/16:0), (d18:1/18:0), and (d18:1/24:1) levels were associated with major adverse CVD events. Whereas, Ceramide (d18:1/22:0) were not associated (141). Javaheri et al., observed significant association of increased circulating concentrations of C16:0 and C18:0 ceramides in participants with HFpEF (142). This study was especially informative, as HFpEF is difficult to diagnose and controversy still exists as to diagnostic algorithms (143). Similarly, another study showed that levels of ceramide and SM with 16-carbon acyl chain length were directly associated with higher risk of mortality deaths from CVD (144). Analysis of myocardial tissue and serum from patients with HF showed increased ceramide, the significance of which was mainly driven 
by the very long chain ceramides (45). When the HFpEF patients underwent left ventricular assist devices (LVAD) these changes were reversible. In contrast, another study observed that levels of Ceramide with a 22-, or 24-carbon acyl chain length and SM with a 20-, 22-, or 24- carbon acyl chain were directly associated with lower risks of CVD mortality $(142,144)$.

While these biomarkers and diagnostic indicators represent advances in identifying and diagnosing CVD, the distinction between long chain (i.e., C16-C18) and very long chain (i.e., C20-C24) ceramides, which are generated by distinct ceramide synthase isoforms (CerS1/5/6 vs. CerS2/4, respectively) hints at potential mechanistic involvement. However, though much circulating lipid in general arises from liver, a detailed study demonstrated that circulating ceramides but not SM are derived from the endothelium of blood vessels (145). Interestingly the endothelium is functionally impaired in CVDs and could thus contribute to the plasma sphingolipid profile reported in HF. Therefore, further determining the points of origin of these lipids may enable further study on potential mechanistic functions of these lipids in CVD.

\section{DISCUSSION}

In this review we highlighted recent studies implicating sphingolipids in heart development, ischemic injury, and CVDs. In general, the SphK/S1P/S1P receptor signaling axis appears beneficial both in development and in ischemic injury. On the other hand, elevation of myocardial ceramides appears mostly deleterious. Therapeutic potentials of targeting the SphK/S1P/S1P and ceramide pathways are beneficial and have been approved for treatment in patients in other systems, for example the FDA approved FTY-720, an S1P antagonist for treating relapsing multiple sclerosis (146). Since these have been tried in other systems they can be applied to CVDs, as targeting this axis in animal models of CVDs suggested prevention or reversal (147). Targeting CerS1-6 have a great therapeutic potential but there have been multiple developmental roadblocks, however a recent study observed that a CerS1 selective inhibitor endogenously inhibited mitochondrial fatty acid oxidation in muscle and regulated whole-body adiposity, which could potentially benefit in treating patients with some forms of CVDs (148). Further, relationships among circulating sphingolipid species are novel biomarkers of CVD. Therefore, sphingolipid metabolism and signaling is a constant thread from heart development to CVD, with distinct pathways playing beneficial or deleterious roles.

Lipidomic analyses based on mass spectrometry has enabled identification of different sphingoid bases and acyl chain lengths allowing for novel biomarkers in diagnosing and assessing risk in the context of CVDs. These novel risk scores and biomarkers that utilize sphingolipids show the full complexity of the altered lipid metabolism and outperform traditional lipid measurements. Sphingolipid risk scores are better predictors of major adverse cardiac events than conventional risk factors, including total and LDL cholesterol. As such, ceramide testing is now routinely performed as a diagnostic tool in CVD (149-152).
Many studies highlighted in this review contradict one another with respect to the significant sphingolipid species associated with a particular heart development stage or in association with a CVD. It is important to note these controversial observations can arise from the type of lipidomics technology utilized, the size of the population studied, the type of sample collected, sex distribution, and race/ethnicity. For example, an African American healthy control population had significantly higher plasma levels of most SM species and lower levels of lactosylceramide species compared to Caucasian control subjects in the same study (153). These differences were noted in healthy individuals; therefore, stratification of a study population based on race/ethnicity is essential to provide clear conclusions and, moreover, to identify health disparities when considering disease patients between different ethnicities.

Implications of the association of SPTLC3 SNPs with MI and other cardiovascular events is an emergent finding deserving further mechanistic study $(90,91)$. Synthesis of d16-, and d20sphingoid based sphingolipids are entirely dependent while d18-sphingoid based sphingolipids are partially dependent on SPTLC3. Our lab previously showed that $1 / 3^{\text {rd }}$ of the mouse myocardial sphingolipid pool is comprised of d16-sphingoid based sphingolipids presumably derived from SPTLC3 (11). Moreover, HF patients showed reduced SPTLC3 upon placement of left-ventricular assist devices (LVAD) (45). In addition to recognizing the function of SPTLC3 to generate non-canonical sphingoid bases, our understanding of the complexity of sphingolipid metabolism and the diversity of sphingolipid species has exploded in recent years. Thus, when it comes to matters of the heart, untargeted sphingolipidomics has the unique potential for revealing non-canonical sphingolipid species that indicate and/or play mechanistic roles in CVD.

Importantly, while most in vivo studies in the heart that address sphingolipid function have manipulated SPT, either genetically or pharmacologically (e.g., with myriocin treatment), these approaches inhibit biosynthesis of all sphingolipids, both desirable and deleterious, and, therefore, would be much too broad for clinical application. However, identification of specific enzymes that participate in distinct branches and pathways of sphingolipid metabolism would provide much greater specificity for therapeutic intervention in the CVD context. However, the dearth of isoform-specific CerS inhibitors has been an impediment to therapeutic targeting of CerS, though efforts to develop specific agents are beginning to yield results (148).

Over the last decade our lab has focused on studying heart sphingolipids showing that ceramides with not only distinct $\mathrm{N}$-acyl-chains but particular sphingoid base backbone lead to apoptosis, mitochondrial damage and lipotoxicity in cardiomyocytes. It should be noted that identification of specific CerS isoforms that mediate CVD does not necessarily implicate ceramides, per se, but could implicate dihydroceramides as well as downstream products of ceramides including ceramide-1-phosphate, O-acylceramides, sphingomyelin, and glycosphingolipids. This understanding is crucial both for enabling further specificity of therapeutic targeting and facilitating the 
potential identification of additional therapeutic targets. Ultimately, more research is needed to elucidate the regulatory pathways by which sphingolipids regulate cardiogenesis and cardiovascular function in both health and disease.

\section{AUTHOR CONTRIBUTIONS}

LC and AK: writing-review and editing, visualization, and conceptualization. LC, AK, and MJ: writing-original draft

\section{REFERENCES}

1. Hannun YA, Obeid LM. Sphingolipids and their metabolism in physiology and disease. Nat Rev Mol Cell Biol. (2018) 19:175-91. doi: 10.1038/nrm.2017.107

2. Menaldino DS, Bushnev A, Sun A, Liotta DC, Symolon H, Desai K, et al. Sphingoid bases and de novo ceramide synthesis: enzymes involved, pharmacology and mechanisms of action. Pharmacol Res. (2003) 47:37381. doi: 10.1016/S1043-6618(03)00054-9

3. Bushnev A, Hagedorn K, Adiga M, Haynes C, Sullards M, Liotta D, et al. Thematic review series: sphingolipids. Biodiversity of sphingoid bases ("sphingosines") and related amino alcohols. J Lipid Res. (2008) 49:162139. doi: 10.1194/jlr.R800012-JLR200

4. Venkataraman K, Riebeling C, Bodennec J, Riezman H, Allegood JC, Sullards MC, et al. Upstream of growth and differentiation factor 1 (uogl), a mammalian homolog of the yeast longevity assurance gene 1 (LAG1), regulatesN-Stearoyl-sphinganine (C18-(Dihydro) ceramide) synthesis in a fumonisin B1-independent manner in mammalian cells. J Biol Chem. (2002) 277:35642-9. doi: 10.1074/jbc.M205211200

5. Riebeling C, Allegood JC, Wang E, Merrill AH, Futerman AH. Two mammalian longevity assurance gene (LAG1) family members, trh1 and trh4, regulate dihydroceramide synthesis using different fatty acyl-CoA donors. J Biol Chem. (2003) 278:43452-9. doi: 10.1074/jbc.M307104200

6. Laviad EL, Albee L, Pankova-Kholmyansky I, Epstein S, Park H, Merrill AH, et al. Characterization of ceramide synthase 2 tissue distribution, substrate specificity, and inhibition by sphingosine 1-phosphate. J Biol Chem. (2008) 283:5677-84. doi: 10.1074/jbc.M707386200

7. Senkal CE, Salama MF, Snider AJ, Allopenna JJ, Rana NA, Koller A, et al. Ceramide is metabolized to acylceramide and stored in lipid droplets. Cell Metab. (2017) 25:686-97. doi: 10.1016/j.cmet.2017.02.010

8. Aguilar A, Saba JD. Truth and consequences of sphingosine-1-phosphate lyase. Adv Biol Regul. (2012) 52:17-30. doi: 10.1016/j.advenzreg.2011. 09.015

9. Nagiec MM, Baltisberger JA, Wells GB, Lester RL, Dickson RC. The LCB2 gene of saccharomyces and the related LCB1 gene encode subunits of serine palmitoyltransferase, the initial enzyme in sphingolipid synthesis. Proc Natl Acad Sci USA. (1994) 91:7899-902. doi: 10.1073/pnas.91.17.7899

10. Hornemann T, Richard S, Rütti MF, Wei Y, von Eckardstein A. Cloning and initial characterization of a new subunit for mammalian serine-palmitoyltransferase. J Biol Chem. (2006) 281:37275-81. doi: 10.1074/jbc.M608066200

11. Russo SB, Tidhar R, Futerman AH, Cowart LA. Myristate-derived d16:0 sphingolipids constitute a cardiac sphingolipid pool with distinct synthetic routes and functional properties. J Biol Chem. (2013) 288:13397409. doi: 10.1074/jbc.M112.428185

12. Zheng W, Kollmeyer J, Symolon H, Momin A, Munter E, Wang E, et al. Ceramides and other bioactive sphingolipid backbones in health and disease: lipidomic analysis, metabolism and roles in membrane structure, dynamics, signaling and autophagy. Biochim Biophys Acta. (2006) 1758:1864-84. doi: 10.1016/j.bbamem.2006.08.009

13. Sasset L, Zhang Y, Dunn TM, Di Lorenzo A. Sphingolipid de novo biosynthesis: a rheostat of cardiovascular homeostasis. Trends Endocrinol Metab. (2016) 27:807-19. doi: 10.1016/j.tem.2016.07.005 and data curation. LC: supervision and project administration. All authors contributed to the article and approved the submitted version.

\section{FUNDING}

This work was supported in part by a National Heart, Lung, and Blood Institute Grant 1R01HL151243, National Institutes of Health Grant 1R01HL117233, and Veterans Affairs Merit Award 2I0BX000200.

14. Zhang Y, Huang Y, Cantalupo A, Azevedo PS, Siragusa M, Bielawski J, et al. Endothelial Nogo-B regulates sphingolipid biosynthesis to promote pathological cardiac hypertrophy during chronic pressure overload. JCI Insight. (2016) 1:e85484. doi: 10.1172/jci.insight.85484

15. Davis D, Kannan M, Wattenberg B. Orm/ORMDL proteins: gate guardians and master regulators. Adv Biol Regul. (2018) 70:3-18. doi: 10.1016/j.jbior.2018.08.002

16. Park T-S, Hu Y, Noh H-L, Drosatos K, Okajima K, Buchanan J, et al. Ceramide is a cardiotoxin in lipotoxic cardiomyopathy. J Lipid Res. (2008) 49:2101-12. doi: 10.1194/jlr.M800147-JLR200

17. Maekawa K, Hirayama A, Iwata Y, Tajima Y, Nishimaki-Mogami T, Sugawara S, et al. Global metabolomic analysis of heart tissue in a hamster model for dilated cardiomyopathy. J Mol Cell Cardiol. (2013) 59:7685. doi: 10.1016/j.yjmcc.2013.02.008

18. Knapp M, Zendzian-Piotrowska M, Błachnio-Zabielska A, Zabielski P, Kurek K, Górski J. Myocardial infarction differentially alters sphingolipid levels in plasma, erythrocytes and platelets of the rat. Basic Res Cardiol. (2012) 107:294. doi: 10.1007/s00395-012-0294-0

19. Tan G, Zhou Q, Liu K, Dong X, Li L, Liao W, et al. Cross-platform metabolic profiling deciphering the potential targets of shenfu injection against acute viral myocarditis in mice. J Pharm Biomed Anal. (2018) 160:111. doi: 10.1016/j.jpba.2018.07.042

20. Alonso N, Moliner P, Mauricio D. Pathogenesis, clinical features and treatment of diabetic cardiomyopathy. In: Heart Failure: From Research to Clinical Practice. Badalona; Madrid; Lleida; Barcelona: Springer (2017). p. 197-217. doi: 10.1007/5584_2017_105

21. Maceyka M, Harikumar KB, Milstien S, Spiegel S. Sphingosine-1-phosphate signaling and its role in disease. Trends Cell Biol. (2012) 22:50 60. doi: 10.1016/j.tcb.2011.09.003

22. Kupperman E, An S, Osborne N, Waldron S, Stainier DY. A sphingosine1-phosphate receptor regulates cell migration during vertebrate heart development. Nature. (2000) 406:192-5. doi: 10.1038/35018092

23. Matsui T, Raya Á, Callol-Massot C, Kawakami Y, Oishi I, Rodriguez-Esteban $\mathrm{C}$, et al. miles-apart-mediated regulation of cell-fibronectin interaction and myocardial migration in zebrafish. Nat Clin Pract Cardiovasc Med. (2007) 4:S77-82. doi: 10.1038/ncpcardio0764

24. Kawahara A, Nishi T, Hisano Y, Fukui H, Yamaguchi A, Mochizuki N. The sphingolipid transporter spns2 functions in migration of zebrafish myocardial precursors. Science. (2009) 323:524-7. doi: 10.1126/science.1167449

25. de Faria Poloni J, Chapola H, Feltes BC, Bonatto D. The importance of sphingolipids and reactive oxygen species in cardiovascular development. Biol Cell. (2014) 106:167-81. doi: 10.1111/boc.201400008

26. Kraut R. Roles of sphingolipids in drosophila development and disease. $J$ Neurochem. (2011) 116:764-78. doi: 10.1111/j.1471-4159.2010.07022.x

27. Osborne N, Brand-Arzamendi K, Ober EA, Jin S-W, Verkade H, Holtzman NG, et al. The spinster homolog, two of hearts, is required for sphingosine 1-phosphate signaling in zebrafish. Curr Biol. (2008) 18:18828. doi: 10.1016/j.cub.2008.10.061

28. Guzzolino E, Chiavacci E, Ahuja N, Mariani L, Evangelista M, Ippolito C, et al. Post-transcriptional modulation of sphingosine-1-phosphate receptor 1 by miR-19a affects cardiovascular development in zebrafish. Front Cell Dev Biol. (2018) 6:58. doi: 10.3389/fcell.2018.00058 
29. Hisano Y, Inoue A, Taimatsu K, Ota S, Ohga R, Kotani H, et al. Comprehensive analysis of sphingosine-1-phosphate receptor mutants during zebrafish embryogenesis. Genes Cells. (2015) 20:647-58. doi: 10.1111/gtc.12259

30. Hisano Y, Ota S, Takada S, Kawahara A. Functional cooperation of spns2 and fibronectin in cardiac and lower jaw development. Biol Open. (2013) 2:789-94. doi: 10.1242/bio.20134994

31. Mendelson K, Zygmunt T, Torres-Vázquez J, Evans T, Hla T. Sphingosine 1-phosphate receptor signaling regulates proper embryonic vascular patterning. J Biol Chem. (2013) 288:2143-56. doi: 10.1074/jbc.M112.427344

32. Kono M, Mi Y, Liu Y, Sasaki T, Allende ML, Wu Y-P, et al. The sphingosine-1-phosphate receptors S1P1, S1P2, and S1P3 function coordinately during embryonic angiogenesis. J Biol Chem. (2004) 279:2936773. doi: 10.1074/jbc.M403937200

33. Allende ML, Proia RL. Sphingosine-1-phosphate receptors and the development of the vascular system. Biochim Biophys Acta. (2002) 1582:2227. doi: 10.1016/S1388-1981(02)00175-0

34. Wilkerson BA, Grass GD, Wing SB, Argraves WS, Argraves KM. Sphingosine 1-phosphate (S1P) carrier-dependent regulation of endothelial barrier high density lipoprotein (HDL)-S1P prolongs endothelial barrier enhancement as compared with albumin-S1P via effects on levels, trafficking, and signaling of S1P1. J Biol Chem. (2012) 287:44645-53. doi: 10.1074/jbc.M112.423426

35. Wendler CC, Rivkees SA. Sphingosine-1-phosphate inhibits cell migration and endothelial to mesenchymal cell transformation during cardiac development. Dev Biol. (2006) 291:264-77. doi: 10.1016/j.ydbio.2005.12.013

36. Sanna MG, Vincent KP, Repetto E, Nguyen N, Brown SJ, Abgaryan L, et al. Bitopic sphingosine 1-phosphate receptor 3 (S1P3) antagonist rescue from complete heart block: pharmacological and genetic evidence for direct S1P3 regulation of mouse cardiac conduction. Mol Pharmacol. (2016) 89:17686. doi: 10.1124/mol.115.100222

37. Berridge MJ, Lipp P, Bootman MD. The versatility and universality of calcium signalling. Nat Rev Mol Cell Biol. (2000) 1:11-21. doi: 10.1038/35036035

38. zu Heringdorf DM, Lass H, Alemany R, Laser KT, Neumann E, Zhang C, et al. Sphingosine kinase-mediated $\mathrm{Ca} 2+$ signalling by G-protein-coupled receptors. EMBO J. (1998) 17:2830-7. doi: 10.1093/emboj/17.10.2830

39. Mangoni ME, Couette B, Bourinet E, Platzer J, Reimer D, Striessnig J, et al. Functional role of L-type Cav1. $3 \mathrm{Ca} 2+$ channels in cardiac pacemaker activity. Proc Natl Acad Sci USA. (2003) 100:5543-8. doi: 10.1073/pnas.0935295100

40. Zhang Q, Timofeyev V, Lu L, Li N, Singapuri A, Long MK, et al. Functional roles of a Ca2+-activated $\mathrm{K}+$ channel in atrioventricular nodes. Circulat Res. (2008) 102:465-71. doi: 10.1161/CIRCRESAHA.107.161778

41. Mesirca P, Torrente AG, Mangoni ME. Functional role of voltage gated Ca2+ channels in heart automaticity. Front Physiol. (2015) 6:19. doi: 10.3389/fphys.2015.00019

42. Ge D, Yue H-w, Liu H-h, Zhao J. Emerging roles of sphingosylphosphorylcholine in modulating cardiovascular functions and diseases. Acta Pharmacol Sinica. (2018) 39:18306. doi: 10.1038/s41401-018-0036-4

43. Kattman SJ, Huber TL, Keller GM. Multipotent flk-1+ cardiovascular progenitor cells give rise to the cardiomyocyte, endothelial, and vascular smooth muscle lineages. Dev Cell. (2006) 11:723-32. doi: 10.1016/j.devcel.2006.10.002

44. Li W, Liu H, Liu P, Yin D, Zhang S, Zhao J. Sphingosylphosphorylcholine promotes the differentiation of resident Sca-1 positive cardiac stem cells to cardiomyocytes through lipid raft/JNK/STAT3 and $\beta$-catenin signaling pathways. Biochim Biophys Acta. (2016) 1863:1579-88. doi: 10.1016/j.bbamcr.2016.04.006

45. Ji R, Akashi H, Drosatos K, Liao X, Jiang H, Kennel PJ, et al. Increased de novo ceramide synthesis and accumulation in failing myocardium. JCI Insight. (2017) 2:e82922. doi: 10.1172/jci.insight.82922

46. Lee S-Y, Kim JR, Hu Y, Khan R, Kim S-J, Bharadwaj KG, et al. Cardiomyocyte specific deficiency of serine palmitoyltransferase subunit 2 reduces ceramide but leads to cardiac dysfunction. J Biol Chem. (2012) 287:18429-39. doi: 10.1074/jbc.M111.296947

47. Bangari DS, Ashe KM, Desnick RJ, Maloney C, Lydon J, Piepenhagen P, et al. $\alpha$-Galactosidase a knockout mice: progressive organ pathology resembles the type 2 later-onset phenotype of fabry disease. Am J Pathol. (2015) 185:651-65. doi: 10.1016/j.ajpath.2014.11.004

48. Quinta R, Rodrigues D, Assunção M, Macedo MF, Azevedo O, Cunha $\mathrm{D}$, et al. Reduced glucosylceramide in the mouse model of fabry disease: correction by successful enzyme replacement therapy. Gene. (2014) 536:97104. doi: 10.1016/j.gene.2013.11.073

49. Marathe S, Miranda SR, Devlin C, Johns A, Kuriakose G, Williams KJ, et al. Creation of a mouse model for non-neurological (type B) niemann-pick disease by stable, low level expression of lysosomal sphingomyelinase in the absence of secretory sphingomyelinase: relationship between brain intralysosomal enzyme activity and central nervous system function. $\mathrm{Hum} \mathrm{Mol}$ Genet. (2000) 9:1967-76. doi: 10.1093/hmg/9.13.1967

50. Bhat OM, Li G, Yuan X, Huang D, Gulbins E, Kukreja RC, et al. Arterial medial calcification through enhanced small extracellular vesicle release in smooth muscle-specific asah1 gene knockout mice. Sci Rep. (2020) 10:1645. doi: 10.1038/s41598-020-58568-5

51. Bandhuvula P, Honbo N, Wang G-Y, Jin Z-Q, Fyrst H, Zhang M, et al. S1P lyase: a novel therapeutic target for ischemia-reperfusion injury of the heart. Am J Physiol Heart Circul Physiol. (2011) 300:H175361. doi: 10.1152/ajpheart.00946.2010

52. Gorshkova IA, Wang H, Orbelyan GA, Goya J, Natarajan V, Beiser DG, et al. Inhibition of sphingosine-1-phosphate lyase rescues sphingosine kinase1-knockout phenotype following murine cardiac arrest. Life Sci. (2013) 93:359-66. doi: 10.1016/j.lfs.2013.07.017

53. Karliner JS. Sphingosine kinase and sphingosine 1phosphate in cardioprotection. J Cardiovasc Pharmacol. (2009) 53:189. doi: 10.1097/FJC.0b013e3181926706

54. Hisano Y, Inoue A, Okudaira M, Taimatsu K, Matsumoto H, Kotani $\mathrm{H}$, et al. Maternal and zygotic sphingosine kinase 2 are indispensable for cardiac development in zebrafish. J Biol Chem. (2015) 290:1484151. doi: 10.1074/jbc.M114.634717

55. Clay H, Wilsbacher LD, Wilson SJ, Duong DN, McDonald M, Lam I, et al. Sphingosine 1-phosphate receptor-1 in cardiomyocytes is required for normal cardiac development. Dev Biol. (2016) 418:15765. doi: 10.1016/j.ydbio.2016.06.024

56. Means CK, Miyamoto S, Chun J, Brown JH. S1P1 receptor localization confers selectivity for Gi-mediated cAMP and contractile responses. J Biol Chem. (2008) 283:11954-63. doi: 10.1074/jbc.M707422200

57. Theilmeier G, Schmidt C, Herrmann Jr, Keul P, Schäfers M, Herrgott I, et al. Clinical perspective. Circulation. (2006) 114:1403-9. doi: 10.1161/CIRCULATIONAHA.105.607135

58. Means CK, Xiao C-Y, Li Z, Zhang T, Omens JH, Ishii I, et al. Sphingosine 1phosphate S1P2 and S1P3 receptor-mediated Akt activation protects against in vivo myocardial ischemia-reperfusion injury. Am J Physiol Heart Circul Physiol. (2007) 292:H2944-H51. doi: 10.1152/ajpheart.01331.2006

59. Ishii I, Ye X, Friedman B, Kawamura S, Contos JJ, Kingsbury MA, et al. Marked perinatal lethality and cellular signaling deficits in mice null for the two sphingosine 1-phosphate (S1P) receptors, S1P2/LPB2/EDG-5 and S1P3/LPB3/EDG-3. J Biol Chem. (2002) 277:25152-9. doi: 10.1074/jbc.M200137200

60. Skoura A, Michaud J, Im D-S, Thangada S, Xiong Y, Smith JD, et al. Sphingosine-1-phosphate receptor-2 function in myeloid cells regulates vascular inflammation and atherosclerosis. Arterioscler Thromb Vasc Biol. (2011) 31:81-5. doi: 10.1161/ATVBAHA.110.213496

61. Schuchardt M, Tölle M, Huang T, Zidek W, Van Der Giet M. HDL DIMINISHES MMP-9 PRODUCTION IN A S1P3/TGF- $\beta$ DEPENDENT MANNER. J Hypertension. (2011) 29:e186. doi: 10.1097/00004872-201106001-00487

62. Keul P, Lucke S, von Wnuck Lipinski K, Bode C, Gräler M, Heusch $\mathrm{G}$, et al. Sphingosine-1-phosphate receptor 3 promotes recruitment of monocyte/macrophages in inflammation and atherosclerosis. Circulation Res. (2011) 108:314-23. doi: 10.1161/CIRCRESAHA.110.235028

63. Wang X, Rao RP, Kosakowska-Cholody T, Masood MA, Southon E, Zhang $\mathrm{H}$, et al. Mitochondrial degeneration and not apoptosis is the primary cause of embryonic lethality in ceramide transfer protein mutant mice. J Cell Biol. (2009) 184:143-58. doi: 10.1083/jcb.200807176

64. American Heart Association. Cardiovascular Disease: A Costly Burden for America Projections Through. American Heart Association (2017). 
65. Kovilakath A, Cowart LA. Sphingolipid mediators of myocardial pathology. J Lipid Atherosc. (2020) 9:23-49. doi: 10.12997/jla.2020.9.1.23

66. Kovilakath A, Cowart AL. A novel class of sphingolipids mediate autophagy and apoptosis in models of ischemia. Circul Res. (2019) 125(Suppl. 1):A735A. doi: 10.1161/res.125.suppl_1.735

67. Turpin SM, Nicholls HT, Willmes DM, Mourier A, Brodesser S, Wunderlich $\mathrm{CM}$, et al. Obesity-induced CerS6-dependent C16:0 ceramide production promotes weight gain and glucose intolerance. Cell Metab. (2014) 20:67886. doi: 10.1016/j.cmet.2014.08.002

68. Kuzmenko D, Klimentyeva T. Role of ceramide in apoptosis and development of insulin resistance. Biochemistry. (2016) 81:913-27. doi: 10.1134/\$0006297916090017

69. Haus JM, Kashyap SR, Kasumov T, Zhang R, Kelly KR, DeFronzo RA, et al. Plasma ceramides are elevated in obese subjects with type 2 diabetes and correlate with the severity of insulin resistance. Diabetes. (2009) 58:33743. doi: $10.2337 / \mathrm{db} 08-1228$

70. Lopez X, Goldfine AB, Holland WL, Gordillo R, Scherer PE. Plasma ceramides are elevated in female children and adolescents with type 2 diabetes. J Pediatr Endocrinol Metab. (2013) 26:995-8. doi: 10.1515/jpem-2012-0407

71. Kasumov T, Li L, Li M, Gulshan K, Kirwan JP, Liu X, et al. Ceramide as a mediator of non-alcoholic fatty liver disease and associated atherosclerosis. PLoS ONE. (2015) 10:e0126910. doi: 10.1371/journal.pone.0126910

72. Raichur S, Brunner B, Bielohuby M, Hansen G, Pfenninger A, Wang B, et al. The role of C16:0 ceramide in the development of obesity and type 2 diabetes: CerS6 inhibition as a novel therapeutic approach. Mol Metab. (2019) 21:36-50. doi: 10.1016/j.molmet.2018.12.008

73. Choromańska B, Myśliwiec P, Razak Hady H, Dadan J, Myśliwiec H, Chabowski A, et al. Metabolic syndrome is associated with ceramide accumulation in visceral adipose tissue of women with morbid obesity. Obesity. (2019) 27:444-53. doi: 10.1002/oby.22405

74. Torretta E, Barbacini P, Al-Daghri NM, Gelfi C. Sphingolipids in obesity and correlated co-morbidities: the contribution of gender, age and environment. Int J Mol Sci. (2019) 20:5901. doi: 10.3390/ijms20235901

75. Boon J, Hoy AJ, Stark R, Brown RD, Meex RC, Henstridge DC, et al. Ceramides contained in LDL are elevated in type 2 diabetes and promote inflammation and skeletal muscle insulin resistance. Diabetes. (2013) 62:40110. doi: $10.2337 / \mathrm{db} 12-0686$

76. Boini KM, Koka S, Xia M, Ritter JK, Gehr TW, Li P-L. Sphingolipids in obesity and related complications. Front Biosci. (2017) 22:4474. doi: $10.2741 / 4474$

77. Chiu H-C, Kovacs A, Ford DA, Hsu F-F, Garcia R, Herrero P, et al. A novel mouse model of lipotoxic cardiomyopathy. J Clin Invest. (2001) 107:81322. doi: 10.1172/JCI10947

78. Yagyu H, Chen G, Yokoyama M, Hirata K, Augustus A, Kako Y, et al. Lipoprotein lipase (LpL) on the surface of cardiomyocytes increases lipid uptake and produces a cardiomyopathy. J Clin Invest. (2003) 111:41926. doi: 10.1172/JCI16751

79. Liu L, Shi X, Bharadwaj KG, Ikeda S, Yamashita H, Yagyu H, et al. DGAT1 expression increases heart triglyceride content but ameliorates lipotoxicity. $J$ Biol Chem. (2009) 284:36312-23. doi: 10.1074/jbc.M109.049817

80. Liu L, Yu S, Khan RS, Homma S, Schulze PC, Blaner WS, et al. Diacylglycerol acyl transferase 1 overexpression detoxifies cardiac lipids in PPAR $\gamma$ transgenic mice. J Lipid Res. (2012) 53:1482-92. doi: 10.1194/jlr.M024208

81. Liu L, Trent CM, Fang X, Son N-H, Jiang H, Blaner WS, et al. Cardiomyocyte-specific loss of diacylglycerol acyltransferase 1 (DGAT1) reproduces the abnormalities in lipids found in severe heart failure. J Biol Chem. (2014) 289:29881-91. doi: 10.1074/jbc.M114.601864

82. Ellis JM, Mentock SM, DePetrillo MA, Koves TR, Sen S, Watkins SM, et al. Mouse cardiac acyl coenzyme a synthetase 1 deficiency impairs fatty acid oxidation and induces cardiac hypertrophy. Mol Cell Biol. (2011) 31:125262. doi: 10.1128/MCB.01085-10

83. Goldenberg JR, Carley AN, Ji R, Zhang X, Fasano M, Schulze PC, et al. Preservation of acyl coenzyme a attenuates pathological and metabolic cardiac remodeling through selective lipid trafficking. Circulation. (2019) 139:2765-77. doi: 10.1161/CIRCULATIONAHA.119.039610

84. Hu W, Bielawski J, Samad F, Merrill AH, Cowart LA. Palmitate increases sphingosine-1-phosphate in $\mathrm{C} 2 \mathrm{C} 12$ myotubes via upregulation of sphingosine kinase message and activity. J Lipid Res. (2009) 50:185262. doi: 10.1194/jlr.M800635-JLR200

85. Hu W, Ross J, Geng T, Brice SE, Cowart LA. Differential regulation of dihydroceramide desaturase by palmitate versus monounsaturated fatty acids Implications for insulin resistance. J Biolo Chem. (2011) 286:16596605. doi: $10.1074 /$ jbc.M110.186916

86. Ross JS, Hu W, Rosen B, Snider AJ, Obeid LM, Cowart LA. Sphingosine kinase 1 is regulated by peroxisome proliferator-activated receptor $\alpha$ in response to free fatty acids and is essential for skeletal muscle interleukin6 production and signaling in diet-induced obesity. J Biol Chem. (2013) 288:22193-206. doi: 10.1074/jbc.M113.477786

87. Russo SB, Baicu CF, Van Laer A, Geng T, Kasiganesan H, Zile MR, et al. Ceramide synthase 5 mediates lipid-induced autophagy and hypertrophy in cardiomyocytes. J Clin Invest. (2012) 122:3919-30. doi: 10.1172/JCI63888

88. Law BA, Liao X, Moore KS, Southard A, Roddy P, Ji R, et al. Lipotoxic very-long-chain ceramides cause mitochondrial dysfunction, oxidative stress, and cell death in cardiomyocytes. FASEB J. (2018) 32:140316. doi: $10.1096 / f j .201700300 \mathrm{R}$

89. Chaurasia B, Summers SA. Ceramides-lipotoxic inducers of metabolic disorders. Trends Endocrinol Metab. (2015) 26:53850. doi: 10.1016/j.tem.2015.07.006

90. Hicks AA, Pramstaller PP, Johansson Å, Vitart V, Rudan I, Ugocsai P, et al. Genetic determinants of circulating sphingolipid concentrations in European populations. PLoS Genet. (2009) 5:e1000672. doi: 10.1371/journal.pgen.1000672

91. Cresci S, Zhang R, Yang Q, Duncan MS, Xanthakis V, Jiang X, et al. Genetic architecture of circulating very-long-chain (C24:0 and C22:0) ceramide concentrations. J Lipid Atherosc. (2020) 9:172-83. doi: 10.12997/jla.2020.9.1.172

92. Alessenko A, Lebedev A, Kurochkin I. The role of sphingolipids in cardiovascular pathologies. Biochem. (2019) 13:12231. doi: $10.1134 / \mathrm{S} 1990750819020021$

93. Kurano M, Yatomi Y. Sphingosine 1-phosphate and atherosclerosis. $J$ Atheroscler Thromb. (2017) 25:16-26. doi: 10.5551/jat.RV17010

94. Okajima F. Plasma lipoproteins behave as carriers of extracellular sphingosine 1-phosphate: is this an atherogenic mediator or an anti-atherogenic mediator? Biochim Biophys Acta. (2002) 1582:132-7. doi: 10.1016/S1388-1981(02)00147-6

95. Peters SL, Alewijnse AE. Sphingosine-1-phosphate signaling in the cardiovascular system. Curr Opin Pharmacol. (2007) 7:186-92. doi: 10.1016/j.coph.2006.09.008

96. Soltau I, Mudersbach E, Geissen M, Schwedhelm E, Winkler MS, Geffken $M$, et al. Serum-sphingosine-1-phosphate concentrations are inversely associated with atherosclerotic diseases in humans. PLOS ONE. (2016) 11:e0168302. doi: 10.1371/journal.pone.0168302

97. Baranowski M, Górski J. Heart sphingolipids in health and disease. Sphing Metab Disease. Białystok: Springer. (2011). p. 41-56. doi: 10.1007/978-1-4614-0650-1_3

98. Borodzicz S, Czarzasta K, Kuch M, Cudnoch-Jedrzejewska A. Sphingolipids in cardiovascular diseases and metabolic disorders. Lipids Health Dis. (2015) 14:55. doi: 10.1186/s12944-015-0053-y

99. Park T-S, Goldberg IJ. Sphingolipids, lipotoxic cardiomyopathy, and cardiac failure. Heart Failure Clin. (2012) 8:633-41. doi: 10.1016/j.hfc.2012. 06.003

100. Keul P, van Borren MM, Ghanem A, Müller FU, Baartscheer A, Verkerk $\mathrm{AO}$, et al. Sphingosine-1-phosphate receptor 1 regulates cardiac function by modulating $\mathrm{Ca} 2+$ sensitivity and $\mathrm{Na}+/ \mathrm{H}+$ exchange and mediates protection by ischemic preconditioning. J Am Heart Assoc. (2016) 5:e003393. doi: 10.1161/JAHA.116.003393

101. Levkau B. Cardiovascular effects of sphingosine-1-phosphate (S1P). Sphingolipids in Disease: Essen: Springer. (2013). p. 147-70. doi: 10.1007/978-3-7091-1511-4_8

102. Yung BS, Brand CS, Xiang SY, Gray CB, Means CK, Rosen H, et al. Selective coupling of the S1P3 receptor subtype to S1P-mediated RhoA activation and cardioprotection. J Mol Cell Cardiol. (2017) 103:110. doi: 10.1016/j.yjmcc.2016.12.008

103. Brait VH, Tarrasón G, Gavaldà A, Godessart N, Planas AM. Selective sphingosine 1-phosphate receptor 1 agonist is 
protective against ischemia/reperfusion in mice. Stroke. 47:3053-6. doi: 10.1161/STROKEAHA.116.015371

104. Sugahara K, Maeda Y, Shimano K, Mogami A, Kataoka H, Ogawa K, et al. Amiselimod, a novel sphingosine 1-phosphate receptor-1 modulator, has potent therapeutic efficacy for autoimmune diseases, with low bradycardia risk. Br J Pharmacol. (2017) 174:15-27. doi: 10.1111/bph.13641

105. Cannavo A, Liccardo D, Komici K, Corbi G, de Lucia C, Femminella GD, et al. Sphingosine kinases and sphingosine 1-phosphate receptors: signaling and actions in the cardiovascular system. Front Pharmacol. (2017) 8:556. doi: $10.3389 /$ fphar.2017.00556

106. Herzog C, Schmitz M, Levkau B, Herrgott I, Mersmann J, Larmann J, et al. Intravenous sphingosylphosphorylcholine protects ischemic and postischemic myocardial tissue in a mouse model of myocardial ischemia/reperfusion injury. Mediat Inflamm. (2010) 2010:425191. doi: 10.1155/2010/425191

107. Hofmann U, Burkard N, Vogt C, Thoma A, Frantz S, Ertl G, et al. Protective effects of sphingosine-1-phosphate receptor agonist treatment after myocardial ischaemia-reperfusion. Cardiovasc Res. (2009) 83:28593. doi: $10.1093 / \mathrm{cvr} / \mathrm{cvp} 137$

108. Fryer RM, Muthukumarana A, Harrison PC, Mazurek SN, Chen RR, Harrington KE, et al. The clinically-tested S1P receptor agonists, FTY720 and BAF312, demonstrate subtype-specific bradycardia (S1P1) and hypertension (S1P3) in rat. PLoS ONE. (2012) 7:e0052985. doi: 10.1371/journal.pone.0052985

109. Egom EEA, Ke Y, Musa H, Mohamed TM, Wang T, Cartwright E, et al. FTY720 prevents ischemia/reperfusion injury-associated arrhythmias in an ex vivo rat heart model via activation of Pak1/Akt signaling. J Mol Cell Cardiol. (2010) 48:406-14. doi: 10.1016/j.yjmcc.2009.10.009

110. Santos-Gallego CG, Vahl TP, Goliasch G, Picatoste B, Arias T, Ishikawa $\mathrm{K}$, et al. Sphingosine-1-phosphate receptor agonist fingolimod increases myocardial salvage and decreases adverse postinfarction left ventricular remodeling in a porcine model of ischemia/reperfusion. Circulation. (2016) 133:954-66. doi: 10.1161/CIRCULATIONAHA.115.012427

111. Goltz D, Huss S, Ramadori E, Büttner R, Diehl L, Meyer R. Immunomodulation by splenectomy or by FTY 720 protects the heart against ischemia reperfusion injury. Clin Exp Pharmacol Physiol. (2015) 42:1168-77. doi: 10.1111/1440-1681.12465

112. Liu X, Wu J, Zhu C, Liu J, Chen X, Zhuang T, et al. Endothelial S1pr1 regulates pressure overload-induced cardiac remodelling through AKTeNOS pathway. J Cell Mol Med. (2019) 24:2013-26. doi: 10.1111/jcmm.14900

113. Pan W, Yu J, Shi R, Yan L, Yang T, Li Y, et al. Elevation of ceramide and activation of secretory acid sphingomyelinase in patients with acute coronary syndromes. Coronary Artery Dis. (2014) 25:2305. doi: 10.1097/MCA.0000000000000079

114. Modrzejewski W, Knapp M, Dobrzyn A, Musial W, Górski J. Ceramides and adhesive molecules in stable ischaemic heart disease. Przeglad lekarski. (2008) 65:131-4.

115. Cordis G, Yoshida T, Das D. HPTLC analysis of sphingomylein, ceramide and sphingosine in ischemic/reperfused rat heart. J Pharm Biomed Anal. (1998) 16:1189-93. doi: 10.1016/S0731-7085(97)00260-4

116. Knapp M, Lisowska A, Zabielski P, Musiał W, Baranowski M. Sustained decrease in plasma sphingosine-1-phosphate concentration and its accumulation in blood cells in acute myocardial infarction. Prostaglandins Other Lipid Mediat. (2013) 106:53-61. doi: 10.1016/j.prostaglandins.2013.10.001

117. Cui J, Engelman RM, Maulik N, Das DK. Role of ceramide in ischemic preconditioning. J Am Coll Surg. (2004) 198:7707. doi: 10.1016/j.jamcollsurg.2003.12.016

118. Zhang DX, Fryer RM, Hsu AK, Zou A-P, Gross GJ, Campbell WB, et al. Production and metabolism of ceramide in normal and ischemicreperfused myocardium of rats. Basic Res Cardiol. (2001) 96:26774. doi: 10.1007/s003950170057

119. Beresewicz A, Dobrzyn A, Gorski J. Accumulation of specific ceramides in ischemic/reperfused rat heart; effect of ischemic preconditioning. J Physiol Pharmacol. (2002) 53:371-82.

120. Cavalli AL, Ligutti JA, Gellings NM, Castro E, Page M, Klepper R, et al. The role of TNF $\alpha$ and sphingolipid signaling in cardiac hypoxia: evidence that cardiomyocytes release TNF $\alpha$ and sphingosine. Basic Appl Myol. (2002) $12: 167-75$.

121. Jin Z-Q, Zhang J, Huang Y, Hoover HE, Vessey DA, Karliner JS. A sphingosine kinase 1 mutation sensitizes the myocardium to ischemia/reperfusion injury. Cardiovasc Res. (2007) 76:4150. doi: 10.1016/j.cardiores.2007.05.029

122. Karliner JS, Honbo N, Summers K, Gray MO, Goetzl EJ. The lysophospholipids sphingosine-1-phosphate and lysophosphatidic acid enhance survival during hypoxia in neonatal rat cardiac myocytes. J Mol Cell Cardiol. (2001) 33:1713-7. doi: 10.1006/jmcc.2001.1429

123. Vessey DA, Kelley M, Li L, Huang Y, Zhou H-Z, Zhu BQ, et al. Role of sphingosine kinase activity in protection of heart against ischemia reperfusion injury. Med Sci Monit. (2006) 12:BR318-24.

124. Vessey DA, Li L, Jin Z-Q, Kelley M, Honbo N, Zhang J, et al. A sphingosine kinase form 2 knockout sensitizes mouse myocardium to ischemia/reoxygenation injury and diminishes responsiveness to ischemic preconditioning. Oxid Med Cell Longev. (2011) 2011:961059. doi: 10.1155/2011/961059

125. Adamy C, Mulder P, Khouzami L, Andrieu-Abadie N, Defer N, Candiani G, et al. Neutral sphingomyelinase inhibition participates to the benefits of $\mathrm{N}$-acetylcysteine treatment in post-myocardial infarction failing heart rats. $J$ Mol Cell Cardiol. (2007) 43:344-53. doi: 10.1016/j.yjmcc.2007.06.010

126. Pavoine C, Pecker F. Sphingomyelinases: their regulation and roles in cardiovascular pathophysiology. Cardiovasc Res. (2009) 82:175-83. doi: $10.1093 / \mathrm{cvr} / \mathrm{cvp} 030$

127. Klevstig M, Ståhlman M, Lundqvist A, Täng MS, Fogelstrand P, Adiels $\mathrm{M}$, et al. Targeting acid sphingomyelinase reduces cardiac ceramide accumulation in the post-ischemic heart. J Mol Cell Cardiol. (2016) 93:6972. doi: 10.1016/j.yjmcc.2016.02.019

128. Kikas P, Chalikias G, Tziakas D. Cardiovascular implications of sphingomyelin presence in biological membranes. Eur Cardiol Rev. (2018) 13:42-45. doi: 10.15420/ecr.2017:20:3

129. Deutschman DH, Carstens JS, Klepper RL, Smith WS, Page MT, Young TR, et al. Predicting obstructive coronary artery disease with serum sphingosine-1-phosphate. Am Heart J. (2003) 146:62-8. doi: 10.1016/S0002-8703(03)00118-2

130. Vessey DA, Li L, Kelley M, Zhang J, Karliner JS. Sphingosine can pre-and post-condition heart and utilizes a different mechanism from sphingosine 1-phosphate. J Biochem Mol Toxicol. (2008) 22:113-8. doi: 10.1002/jbt.20227

131. Vessey DA, Kelley M, Li L, Huang Y. Sphingosine protects aging hearts from ischemia/reperfusion injury: superiority to sphingosine 1-phosphate and ischemic pre-and post-conditioning. Oxidati Med Cell Longev. (2009) 2:146-51. doi: 10.4161/oxim.2.3.8622

132. Cuvillier O. Sphingosine in apoptosis signaling. Biochim Biophys Acta. (2002) 1585:153-62. doi: 10.1016/S1388-1981(02)00336-0

133. Taha TA, Mullen TD, Obeid LM. A house divided: ceramide, sphingosine, and sphingosine-1-phosphate in programmed cell death. Biochim Biophys Acta. (2006) 1758:2027-36. doi: 10.1016/j.bbamem.2006.10.018

134. Pyne S. Cellular signaling by sphingosine and sphingosine 1-phosphate. In: Phosphol Metabolism in Apoptosis: Glasgow: Springer (2004). p. 24568. doi: 10.1007/0-306-47931-1_13

135. Summers SA. Could ceramides become the new cholesterol? Cell Metab. (2018) 27:276-80. doi: 10.1016/j.cmet.2017.12.003

136. Zordoky BN, Sung MM, Ezekowitz J, Mandal R, Han B, Bjorndahl TC, et al. Metabolomic fingerprint of heart failure with preserved ejection fraction. PLoS ONE. (2015) 10:e0124844. doi: 10.1371/journal.pone.0124844

137. Cadby G, Melton PE, McCarthy NS, Giles C, Mellett NA, Huynh K, et al. Heritability of 596 lipid species and genetic correlation with cardiovascular traits in the busselton family heart study. J Lipid Res. (2020) 61:53745. doi: 10.1194/jlr.RA119000594

138. Tabassum R, Rämö JT, Ripatti P, Koskela JT, Kurki M, Karjalainen J, et al. Genetic architecture of human plasma lipidome and its link to cardiovascular disease. Nat Commun. (2019) 10:4329. doi: 10.1038/s41467-019-11954-8

139. Bellis C, Kulkarni H, Mamtani M, Kent Jr JW, Wong G, Weir $\mathrm{JM}$, et al. Human plasma lipidome is pleiotropically associated with cardiovascular risk factors and death. Circul Cardiovasc Genet. (2014) 7:85463. doi: 10.1161/CIRCGENETICS. 114.000600 
140. Demirkan A, Pool R, Deelen J, Beekman M, Liu J, Harms AC, et al. Genomewide association study of plasma triglycerides, phospholipids and relation to cardio-metabolic risk factors. bioRxiv. 2019:621334. doi: 10.1101/6 21334

141. Mantovani A, Dugo C. Ceramides and risk of major adverse cardiovascular events: a meta-analysis of longitudinal studies. J Clin Lipidol. (2020) 14:17685. doi: 10.1016/j.jacl.2020.01.005

142. Javaheri A, Allegood JC, Cowart LA, Chirinos JA. Circulating ceramide 16:0 in heart failure with preserved ejection fraction. J Am Coll Cardiol. (2020) 75:2273-5. doi: 10.1016/j.jacc.2020.02.062

143. Tadic M, Cuspidi C, Calicchio F, Grassi G, Mancia G. Diagnostic algorithm for HFpEF: how much is the recent consensus applicable in clinical practice? Heart Failure Rev. (2020). doi: 10.1007/s10741-020-09966-4. [Epub ahead of print].

144. Fretts AM, Jensen P, Hoofnagle A, McKnight B, Sitlani C, Siscovick DS, et al. Abstract P492: circulating sphingolipids and risk of mortality: the cardiovascular health study. Circulation. (2020) 141(Suppl. 1):AP492. doi: 10.1161/circ.141.suppl_1.P492

145. Cantalupo A, Sasset L, Gargiulo A, Rubinelli L, Del Gaudio I, Benvenuto $\mathrm{D}$, et al. Endothelial sphingolipid de novo synthesis controls blood pressure by regulating signal transduction and $\mathrm{NO}$ via ceramide. Hypertension. (2020) 75:1279-88. doi: 10.1161/HYPERTENSIONAHA.119. 14507

146. Chun J, Brinkmann V. A mechanistically novel, first oral therapy for multiple sclerosis: the development of fingolimod (FTY720, Gilenya). Discov Med. (2011) 12:213.

147. Liu W, Zi M, Tsui H, Chowdhury SK, Zeef L, Meng Q-J, et al. A novel immunomodulator, FTY-720 reverses existing cardiac hypertrophy and fibrosis from pressure overload by targeting NFAT (nuclear factor of activated T-cells) signaling and periostin. Circul Heart Failure. (2013) 6:833-44. doi: 10.1161/CIRCHEARTFAILURE.112.0 00123
148. Turner N, Lim XY, Toop HD, Osborne B, Brandon AE, Taylor EN, et al. A selective inhibitor of ceramide synthase 1 reveals a novel role in fat metabolism. Nat Commun. (2018) 9:3615. doi: 10.1038/s41467-018-05613-7

149. Nicholls M. Plasma ceramides and cardiac risk. Eur Heart J. (2017) 38:135960. doi: 10.1093/eurheartj/ehx205

150. Poss AM, Holland WL, Summers SA. Risky lipids: refining the ceramide score that measures cardiovascular health. Eur Heart J. (2020) 41:3812. doi: 10.1093/eurheartj/ehz525

151. Hilvo M, Meikle PJ, Pedersen ER, Tell GS, Dhar I, Brenner $\mathrm{H}$ et al. Development and validation of a ceramide-and phospholipid-based cardiovascular risk estimation score for coronary artery disease patients. Eur Heart J. (2020) 41:371-80. doi: 10.1093/eurheartj/ehz387

152. Nwabuo CC, Duncan M, Xanthakis V, Peterson LR, Mitchell GF, McManus $\mathrm{D}$, et al. Association of circulating ceramides with cardiac structure and function in the community: the framingham heart study. J Am Heart Assoc. (2019) 8:e013050. doi: 10.1161/JAHA.119.013050

153. Hammad SM, Hardin JR, Wilson DA, Twal WO, Nietert PJ, Oates JC. Race disparity in blood sphingolipidomics associated with lupus cardiovascular comorbidity. PLoS ONE. (2019) 14:e0224496. doi: 10.1371/journal.pone.0224496

Conflict of Interest: The authors declare that the research was conducted in the absence of any commercial or financial relationships that could be construed as a potential conflict of interest.

Copyright (c) 2020 Kovilakath, Jamil and Cowart. This is an open-access article distributed under the terms of the Creative Commons Attribution License (CC BY). The use, distribution or reproduction in other forums is permitted, provided the original author(s) and the copyright owner(s) are credited and that the original publication in this journal is cited, in accordance with accepted academic practice. No use, distribution or reproduction is permitted which does not comply with these terms. 